\title{
Multiple Uveal Melanoma
}

\author{
Wajiha J. Kheir Jane S. Kim Miguel Angel Materin \\ Duke Eye Center, Duke University School of Medicine, Durham, NC, USA
}

\begin{abstract}
Keywords
Bilateral choroidal/uveal melanoma - Unilateral multiple choroidal/uveal melanoma - Unilateral multifocal choroidal/uveal melanoma · Intraocular metastasis . Interocular metastasis - Contralateral metastasis · BAP1 . $B R C A 2 \cdot$ Oculodermal melanocytosis
\end{abstract}

\begin{abstract}
Introduction: Multiple uveal melanoma is a rare occurrence and includes bilateral melanoma, unilateral multiple/multifocal melanoma, or melanoma with metastasis to the ipsilateral or contralateral eye. Methods: A chart review of patients diagnosed with uveal melanoma between January 2013 and January 2019 at the Duke University Eye Center Ophthalmic Oncology Service was performed. Results: Three patients with multiple, sequential melanoma were identified; patient 1 had bilateral choroidal melanoma and patients 2 and 3 had 2 choroidal melanomas occurring in the same eye. In all 3 patients, both the first and sequential choroidal melanomas were treated with I-125 radioactive plaque brachytherapy (PBT). Two patients were found to have developed secondary metastatic uveal melanoma as a presenting sign of systemic metastases. Patient 4, initially treated with PBT, was diagnosed with ipsilateral metastatic choroidal melanoma, also treated with PBT. Patient 5 had right eye enucleation for choroidal melanoma and developed vision-threatening me-
\end{abstract}

tastasis in the left eye, which was treated with PBRT. None of the patients had history of cancer prior to their first diagnosis. Patients 1 and 5 were tested with a systemic melanoma panel; both were negative for $B A P 1$, but patient 1 had a variant of unknown significance in BRCA2. Patient 3 had oculodermal melanocytosis, an established risk factor of uveal melanoma. Conclusion: Although rare, the possibility of multiple uveal melanoma does exist. Examination of the treated and contralateral eye on a regular basis is crucial, not only to identify local failure but also new metastases from the primary tumor and additional primary tumors.

() 2020 S. Karger AG, Basel

\section{Introduction}

The incidence of uveal melanoma in the USA has been estimated to be 5.1-5.2 per million [1-3]. Having a diagnosis of uveal melanoma more than once in a lifetime is expected to be exceedingly rare but has been reported either as bilateral melanoma [4-13], unilateral multiple/ multifocal melanoma [14-22], or melanoma with metastasis to the ipsilateral $[21,23]$ or contralateral [24-28] eye. In this chart review, our aim is to identify any such cases among patients who have been diagnosed and treated for uveal melanoma at the Duke University Eye Center (DUEC) Ophthalmic Oncology Center.

$\begin{aligned} & \text { karger@karger.com } \\ & \text { www.karger.com/oop }\end{aligned}$
Karger $\%$

Miguel Angel Materin 
Table 1. Summary of the patients with multiple uveal melanoma and a description of their tumors

\begin{tabular}{|c|c|c|c|c|c|c|c|c|c|c|}
\hline $\begin{array}{l}\text { Case } \\
\text { No. }\end{array}$ & $\begin{array}{l}\text { Predisposing } \\
\text { factors }\end{array}$ & $\begin{array}{l}\text { Metastasis } \\
\text { (as of } \\
\text { publication) }\end{array}$ & $\begin{array}{l}\text { Time elapsed } \\
\text { between } \\
\text { diagnoses, } \\
\text { months }\end{array}$ & Tumor & Eye & Location & Treatment & Biopsy & GEP class & PRAME \\
\hline 1 & $\begin{array}{l}\text { BRCA2 mutation } \\
\text { Caucasian }\end{array}$ & None & 0 & $\begin{array}{l}\text { Tumor } 1 \\
\text { Tumor } 2\end{array}$ & $\begin{array}{l}\text { OS } \\
\text { OD }\end{array}$ & $\begin{array}{l}\text { Temporal posterior pole } \\
\text { Infratemporal periphery }\end{array}$ & $\begin{array}{l}\text { PBT } \\
\text { PBT }\end{array}$ & $\begin{array}{l}\text { Transscleral } \\
\text { Transvitreal }\end{array}$ & $\begin{array}{l}\text { Class } 2 \\
\text { Class } 2\end{array}$ & $\begin{array}{l}\text { Positive } \\
\text { Positive }\end{array}$ \\
\hline 2 & Caucasian & None & 60 & $\begin{array}{l}\text { Tumor } 1 \\
\text { Tumor } 2\end{array}$ & $\begin{array}{l}\text { OD } \\
\text { OD }\end{array}$ & $\begin{array}{l}\text { Nasal periphery } \\
\text { Temporal periphery }\end{array}$ & $\begin{array}{l}\text { PBT } \\
\text { PBT }\end{array}$ & $\begin{array}{l}\text { Transscleral } \\
\text { Transscleral }\end{array}$ & $\begin{array}{l}\text { Class } 2 \\
\text { Class } 2\end{array}$ & $\begin{array}{l}\text { NA } \\
\text { Negative }\end{array}$ \\
\hline 3 & $\begin{array}{l}\text { Oculodermal } \\
\text { melanocytosis } \\
\text { Caucasian }\end{array}$ & None & 47 & $\begin{array}{l}\text { Tumor } 1 \\
\text { Tumor } 2\end{array}$ & $\begin{array}{l}\text { OD } \\
\text { OD }\end{array}$ & $\begin{array}{l}\text { Supratemporal arcade } \\
\text { Infratemporal periphery }\end{array}$ & $\begin{array}{l}\text { PBT } \\
\text { PBT }\end{array}$ & $\begin{array}{l}\text { Transvitreal } \\
\text { Transscleral }\end{array}$ & $\begin{array}{l}\text { Class } 1 \mathrm{~A} \\
\text { Class } 2\end{array}$ & $\begin{array}{l}\text { NA } \\
\text { Negative }\end{array}$ \\
\hline 4 & Caucasian & Yes & 84 & $\begin{array}{l}\text { Tumor } 1 \\
\text { Tumor } 2\end{array}$ & $\begin{array}{l}\text { OS } \\
\text { OS }\end{array}$ & $\begin{array}{l}\text { Infratemporal arcade } \\
\text { Inferior periphery }\end{array}$ & $\begin{array}{l}\text { PBT } \\
\text { PBT }\end{array}$ & $\begin{array}{l}\text { None } \\
\text { None }\end{array}$ & $\begin{array}{l}\text { NA } \\
\text { NA }\end{array}$ & $\begin{array}{l}\text { NA } \\
\text { NA }\end{array}$ \\
\hline 5 & Caucasian & Yes & 96 & $\begin{array}{l}\text { Tumor } 1 \\
\text { Tumor } 2\end{array}$ & $\begin{array}{l}\text { OD } \\
\text { OS }\end{array}$ & $\begin{array}{l}\text { Posterior pole } \\
\text { Posterior pole }\end{array}$ & $\begin{array}{l}\text { Enucleation } \\
\text { PBT }\end{array}$ & $\begin{array}{l}\text { None } \\
\text { None }\end{array}$ & $\begin{array}{l}\text { NA } \\
\text { NA }\end{array}$ & $\begin{array}{l}\text { NA } \\
\text { NA }\end{array}$ \\
\hline
\end{tabular}

PBT, plaque brachytherapy; GEP, gene expression profile; PRAME, preferentially expressed antigen in melanoma.

\section{Methods}

After gaining approval from the institutional review board of Duke University Medical Center, an exhaustive chart review of patients diagnosed with uveal melanoma between January 2013 and January 2019 at the DUEC Ophthalmic Oncology Service was performed. Patients with a diagnosis of uveal melanoma (including choroidal, ciliary, and iris) were identified using diagnosis codes from the ICD (International Statistical Classification of Diseases and Related Health Problems) 9 and 10. In patients found to have multiple uveal melanoma, the following information was collected: demographics, ophthalmic exam, ophthalmic imaging results, treatment, biopsy results, metastasis, and survival.

\section{Results}

Out of 764 patients diagnosed with uveal melanoma (iris, ciliary body, or choroid), 5 patients $(0.65 \%)$ were identified to have multiple uveal melanomas. One had bilateral choroidal melanoma, 2 had unilateral multifocal choroidal melanoma, 1 had choroidal melanoma with ipsilateral metastasis as the presenting sign of systemic metastases, and 1 had choroidal melanoma with metastasis to the contralateral eye as the presenting sign of systemic metastases. Two were female and 3 were male with ages at initial diagnosis ranging from 42 to 71 years, and all were Caucasian. None of the patients had any prior history of cancer or any family history of uveal melanoma. The cases are described below and are summarized in Table 1 .

\section{Case 1}

A middle-aged Caucasian patient was referred to the DUEC in January of 2018 for bilateral choroidal melanocytic lesions. In the right eye, there was a lobulated, irregularly shaped melanocytic choroidal lesion in the infratemporal periphery, $15 \times 14 \mathrm{~mm}$ in basal diameter (BD), associated with adjacent subretinal fluid (SRF) but lacking obvious drusen and lipofuscin (Fig. 1a). By A- and $\mathrm{B}$-scan ultrasound (US), it measured $3 \mathrm{~mm}$ in thickness and had low-to-medium internal reflectivity. In the left eye, a $12 \times 12-\mathrm{mm} \mathrm{BD}$ dome-shaped melanocytic choroidal lesion was seen temporal to the fovea (Fig. 1b), which was associated with SRF but lacked obvious drusen and lipofuscin. By US, it measured $4 \mathrm{~mm}$ in thickness and had low internal reflectivity.

A systemic screening consisting of a dermatology consult and a CT of the chest, abdomen, and pelvis was unrevealing. Plaque brachytherapy (PBT) with transscleral fine-needle aspiration biopsy (FNAB) for gene expression profile (GEP) and preferentially expressed antigen in melanoma (PRAME) were performed in the left eye in February 2018. This was followed by PBT with 27-G transvitreal FNAB in the right eye in July 2018.

Regarding the genetic profile of the tumors, the left eye tested as class 2, PRAME negative, while the right eye tested as class 2, PRAME positive. The patient was also tested for mutations in the melanoma panel which revealed a variant of uncertain significance (c.5048A $>$ C [p.Gln1683Pro]) in BRCA2. The patient has undergone systemic screening 

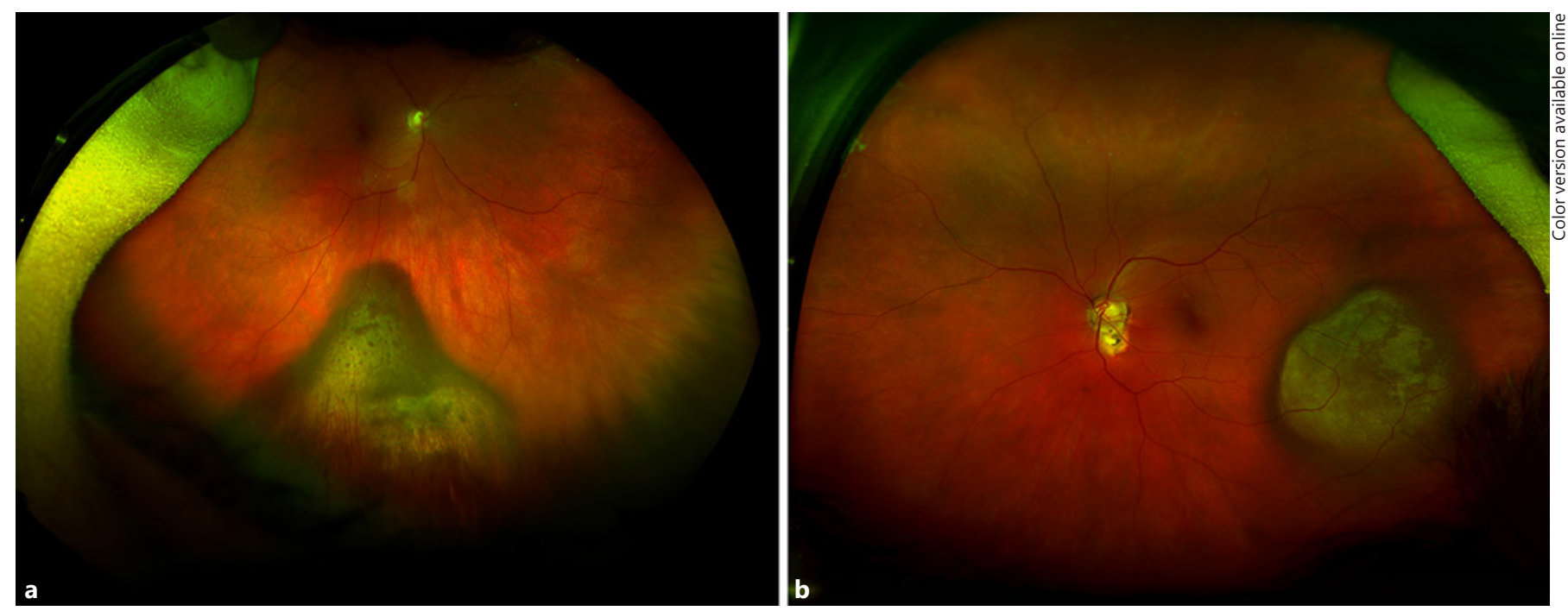

Fig. 1. Fundus photographs of patient 1: tumor 1 in the left eye (a) and tumor 2 in the right eye (b), diagnosed concurrently in 2018.
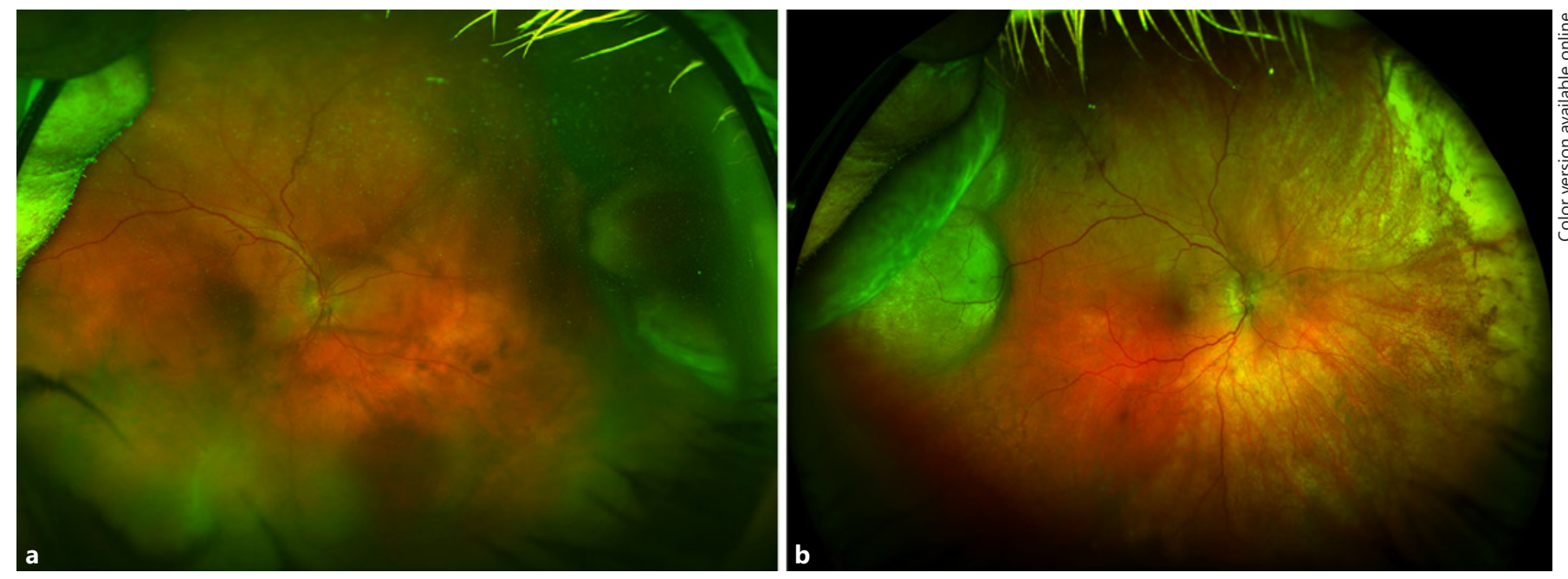

Fig. 2. Patient 2: tumor 1 (a) in the nasal periphery and tumor $2(\mathbf{b})$ in the temporal periphery. The fundus photograph (b) also shows a completely regressed tumor 1 nasally with residual chorioretinal scarring in the right eye.

4 times since diagnosis, and remained metastasis free in the 23 months following the first treatment.

\section{Case 2}

An elderly otherwise healthy Caucasian patient was diagnosed with right ciliochoroidal melanoma in October 2013 at the DUEC. The nasal tumor was $4 \times 15 \mathrm{~mm}$ in BD and $5.35 \mathrm{~mm}$ in thickness, and associated with SRF and a vitreous hemorrhage (Fig. 2a). The tumor underwent PBT, and the transscleral FNAB gave a class 2 GEP classification.
In July 2018, the patient presented for evaluation after having been lost to follow-up since October 2015. In the interim, the patient had been compliant with systemic screening and had remained metastasis free. The treated nasal tumor appeared regressed with extensive scarring; the thickness had decreased from 5.35 to $1.70 \mathrm{~mm}$. A new $15 \times 15-\mathrm{mm}$ multilobulated mass in the far temporal periphery of the right eye without ciliary body involvement was noted (Fig. 2b). It had low-to-medium internal reflectivity, a thickness of $5.8 \mathrm{~mm}$, but no obvious SRF, lipofuscin, or drusen. It is worth noting that the patient did 

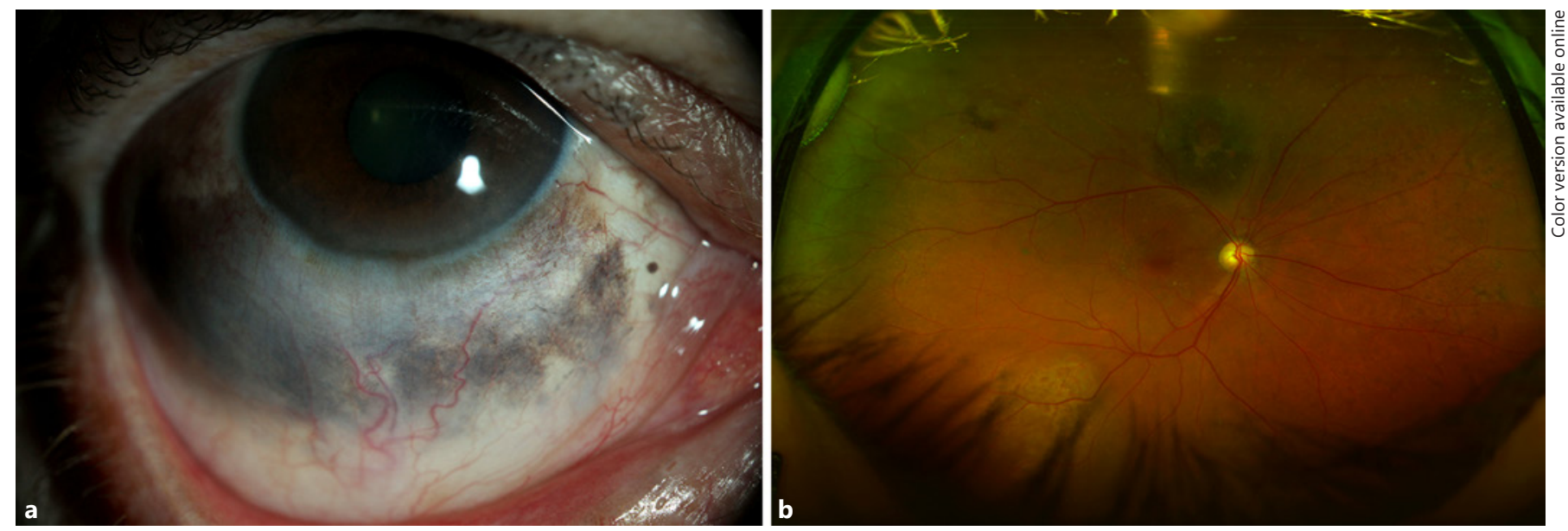

Fig. 3. Patient 3 with ODM. a Slit-lamp photography showing the ocular component. b Fundus photograph showing a regressed tumor 1 at the supratemporal arcade, as well as the newly diagnosed tumor 2 infratemporally in the right eye.

not have oculodermal melanocytosis (ODM)/nevus of Ota.

Considering our high suspicion of a second melanoma in the right eye, the decision for transscleral FNAB was made. Cytology confirmed the diagnosis of choroidal melanoma, and the GEP came back as class 2, PRAME negative. It was treated with PBT in October 2018. The patient remained metastasis free 74 months after the first treatment.

\section{Case 3}

In February 2013, a middle-aged Caucasian patient with right ODM (Fig. 3a) was diagnosed with a $7 \times 7-\mathrm{mm}$ choroidal melanoma with clear SRF, lipofuscin, and no drusen. It had low internal reflectivity on US and measured $2.4 \mathrm{~mm}$ in thickness. It was treated with PBT in March 2013. A 27-G transvitreal FNAB performed at the time of plaque insertion revealed a class $1 \mathrm{~A}$ classification. The patient was metastasis free at the time of diagnosis. The PBT caused regression of the tumor with a definite decrease in thickness.

On regular follow-up examination in January 2017, there was a $10 \times 10$-mm mass infratemporally that was not noted on previous exams. It had associated SRF and lipofuscin, low-to-medium internal reflectivity with mild vascularity on US, and measured $3.5 \mathrm{~mm}$ in thickness (Fig. 3b). Considering the conferred risk from ODM, the patient decided on treatment with PBT. A 25-G transscleral FNAB of the lesion revealed a class 2, PRAMEnegative classification. The patient remained metastasis free in the 82 months following the first treatment.

\section{Case 4}

An elderly Caucasian patient was diagnosed with choroidal melanoma at the DUEC in January 2011. It was a $4.5 \times 6-\mathrm{mm}$ pigmented lesion in the inferior arcade, 2 $\mathrm{mm}$ from the optic nerve and $3 \mathrm{~mm}$ from the fovea, with overlying lipofuscin and a cuff of SRF surrounding it (Fig. 4a). On B-scan, the lesion had low internal reflectivity and a thickness of $2.13 \mathrm{~mm}$. The patient was diagnosed with choroidal melanoma and treatment with PBT without FNAB was performed in February 2011. The patient was metastasis free at the time of diagnosis and treatment.

Over the next 6 years the patient showed regression of the treated choroidal melanoma. At their January 2018 visit, however, a new lesion very far inferior in the periphery of the left eye was noted. It was $7 \times 7 \mathrm{~mm}$ in diameter, $15 \mathrm{~mm}$ from the optic nerve, and lacked SRF, drusen, and lipofuscin (Fig. 4b). US biomicroscopy revealed a domeshaped lesion with a maximal thickness of $4.0 \mathrm{~mm}$ that involved the ciliary body. On transillumination, the tumor exhibited incomplete blockage. After discussion with the patient, close observation was elected. Two months later, the BD of the tumor grew to $10 \mathrm{~mm}$ and the thickness increased to $5 \mathrm{~mm}$. The tumor was treated with PBT in April 2018. FNAB was not performed due to patient preference.

In July 2018, a hypo-enhancing pancreatic body mass was noted on CT of the abdomen; FNA of the mass confirmed the diagnosis of metastatic melanoma. The patient decided against treatment and passed away in January 2019. 
Fig. 4. Fundus photographs of patient 4: tumor 1 (a) diagnosed in January 2011, and tumor 2 (b) diagnosed in January 2018. b Regressed tumor 1 at the inferotemporal arcade and tumor 2 in the far inferior periphery (arrow), both in the left eye. Fundus photographs of Patient 5: tumor 1 (c) in the right eye treated with enucleation in 2010, and tumor 2 (d) in the left eye diagnosed as interocular metastasis.
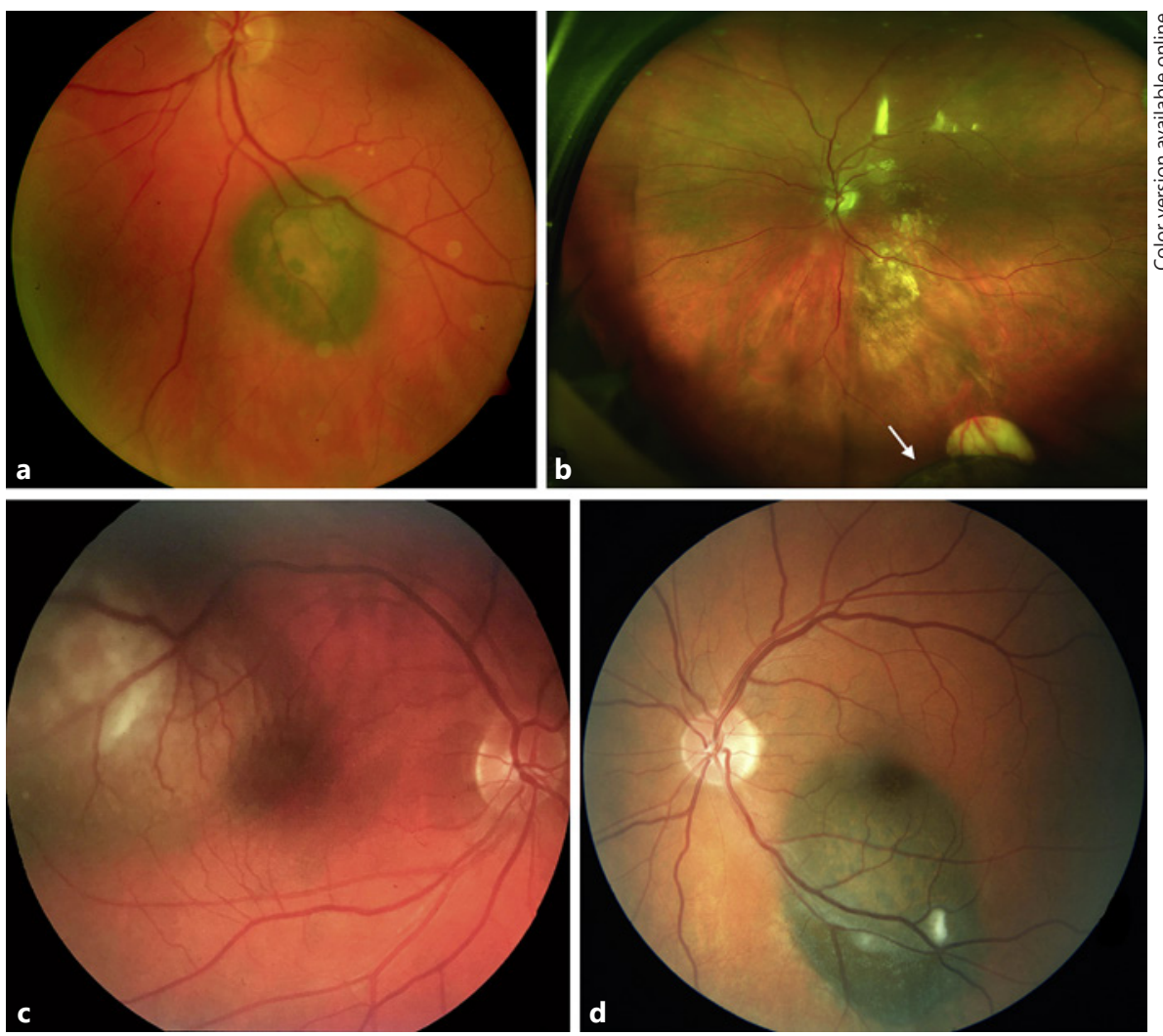

\section{Case 5}

A middle-aged Caucasian patient with history of right eye enucleation for choroidal melanoma in 2010 (Fig. 4c) was referred by a local retina specialist in February 2018 for a suspicious choroidal lesion in the left eye. At the macula, there was a melanocytic choroidal lesion $6 \times 4$ $\mathrm{mm}$ in BD with associated SRF and lipofuscin but no drusen (Fig. 4d). On US, there was a highly reflective lesion measuring $2.0 \mathrm{~mm}$. On reviewing fundus photos from the referring doctor, the patient had no evidence of the lesion in February 2017.

The melanoma panel and BAP1 gene testing were negative for mutations. On systemic screening, multiple illdefined masses were found in the liver suspicious of metastatic disease. Pathology from US-guided biopsy confirmed the presence of malignant cells consistent with melanoma. After a multidisciplinary discussion with oncology and radiation oncology, the decision was made to treat locally and systemically. The tumor was treated with PBT in March 2018 and subsequently demonstrated adequate regression.

Multiple treatment regimens were used (ipilimumab, pembrolizumab, cobimetinib) in combination with radi- ation therapy to treat the metastases. Unfortunately, they were not successful in halting the progression of the disease. The patient passed away in January 2019.

\section{Discussion}

Uveal melanoma has few established risk factors, but an increased incidence has been linked in people of Caucasian race $[29,30]$, and all 5 of our patients were Caucasian. Case 3 also had ODM, a risk factor for uveal melanoma $[29,31]$ with an estimated lifetime prevalence of 1 in 400 in patients with ODM versus 1 in 13,000 in the general population [31]. There is evidence to suggest that melanocytosis is more likely to result in multiple tumors in the same eye [18-20] or in bilateral melanoma when the condition is bilateral $[6,9]$. Singh et al. [6] found a statistically significant difference between the incidence of ocular melanocytosis in bilateral versus unilateral uveal melanoma cases.

The calculated lifetime risk for bilateral uveal melanoma is 1 in 50 million Caucasian people, meaning that 1 case of bilateral melanoma is expected every 18 years in 
the USA [5]. Case 1, in addition to many others published in the past 20 years, would suggest a higher than expected incidence rate, not all accounted for by the presence of ocular melanocytosis [4, 6-11]. Singh et al. [6] found a statistically significant difference between expected and observed incidence in their series of bilateral uveal melanoma. There is no evidence to suggest that bilateral disease portends an increased metastasis risk, the individual tumor profile notwithstanding. In a systematic review comparing bilateral $(n=52)$ to unilateral uveal melanoma $(n=8,915)$ by Scott et al. [13], the authors found no difference in overall survival between the 2 groups of patients.

Scott et al. [13], however, found a significant difference between the treatment methods chosen for the first and second affected eyes in bilateral melanoma. The first eye was more likely to be enucleated, while the second was more likely to be treated in a globe-sparing fashion. Therefore, and despite it still being a very rare occurrence, the possibility of bilateral disease should be presented to patients not choosing globe-salvaging treatment. It should also be mentioned in the discussion of treatments for radiation retinopathy caused by PBT.

The time interval between diagnosis of the first and second tumor can vary significantly. In patient 1 , the bilateral melanomas were diagnosed simultaneously, similarly to cases reported by Seregard et al. [4], Hadden et al. [7], Lois et al. [8], and Cordes and Cook [11]. In their series of bilateral melanoma, Singh et al. [6] reported intervals from 2 to 32 years. The interval between diagnosis of the primary and secondary tumor, therefore, cannot be used to differentiate between a spontaneously occurring second tumor and metastasis to the contralateral eye.

In case 5, the second tumor in the left eye was diagnosed 8 years after right eye enucleation for choroidal melanoma. Because of the concurrent systemic metastasis, the diagnosis of interocular metastasis was made. In other reported cases of metastasis to the contralateral eye, all patients had systemic metastasis to one or multiple sites [24-28]. Although it is possible that a secondary contralateral tumor could represent the only site of metastasis from a primary tumor rather than a spontaneous occurrence, this would be difficult to prove without a detailed tissue or molecular analysis of both tumors. It is worth noting that the GEP in case 1 was class 2 for both eyes; however, one tumor was PRAME positive and the other was PRAME negative. We have no evidence that these prognostication tools are a true reflection of the genetic fingerprint of the tumor rather than just an imprint of this particular stage of tumor development. Without further genetic information, concurrent systemic metastasis thus seems to be the only distinguishing factor between bilateral choroidal melanoma and interocular metastasis.

Regarding multifocal unilateral uveal melanoma, there have been just over 20 cases reported in the literature [14$20,22]$. In our series, it was important to distinguish between the occurrence of a new tumor in the same eye and local recurrence. In each of our cases, however, the secondary tumors were not connected to, along the track of, or even close to the primary tumors. With the advent of FNAB for prognosis prior to treatment, it was a concern that the process of the biopsy did not result in seeding. FNAB complications include vitreous hemorrhage, retinal detachment, and extraocular extension, but to our knowledge there has been no link made between FNA and a diagnosis of a second melanoma in the eye [32-34]. In cases 2 and 3 , which had FNAB of the primary tumors, the primary and secondary tumors were in completely different quadrants, making it highly unlikely that FNAB played any role in the seeding of the tumor.

Case 4 also had unilateral multifocal tumors, but the diagnosis of intraocular metastasis was made based on the subsequent pancreatic and liver metastases detected. Morkos et al. [23] reported a case of intraocular metastasis diagnosed based on response to systemic treatment for concurrent liver and nodal metastases. A recent case series by Durante et al. [21] suggests that in the absence of risk factors (melanocytosis), unilateral multifocal tumors may actually represent intraocular metastasis preceding systemic metastasis. In 4 cases without melanocytosis or systemic metastasis, tumors within the same eye contained the same guanine nucleotide-binding protein subunit alpha-11 (GNA11) mutation. In 3 cases, they contained the same BRCA-associated protein $1(B A P 1) \mathrm{mu}-$ tation [21].

This highlights how genetic analysis has taken the forefront of uveal melanoma research. Two of the patients in our series could be tested for germline mutations in a melanoma panel. One tested positive for a variant of uncertain significance in BRCA2, and both tested negative for $B A P 1$ gene mutations. The studied incidence of $B A P 1$ mutation in uveal melanoma has been calculated to range from 1.6 to $3.2 \%$ in different populations [35-37]. In calculating this incidence rate, Aoude et al. [37] screened both unilateral and bilateral uveal melanoma cases, but whether or not any bilateral cases possessed a BAP1 mutation was not mentioned. Rao et al. [17] reported a case of multifocal uveal melanoma in a patient with asymptomatic renal cell carcinoma and a germline 
BAP1 mutation. Eide et al. [9] used immunohistochemistry to test for $B A P 1$ protein expression and found it expressed in only one eye of a patient with bilateral uveal melanoma. This supports the idea that, although a BAP1 mutation may be a predisposing factor in developing melanoma, there are likely other genes implicated in that process [37].

\section{Conclusion}

After an exhaustive chart review of 764 patients diagnosed with uveal melanoma, 5 patients with multiple uveal melanomas were found: 1 with bilateral choroidal melanoma, 2 with unilateral multifocal choroidal melanoma, 1 with ipsilateral metastasis, and 1 with contralateral eye metastasis. There is evidence to suggest that bilateral uveal melanoma occurs at a greater than expected rate. Short of more advanced tumor gene testing, differentiating bilateral melanoma from contralateral metastasis and unilateral multifocal melanoma from ipsilateral metastasis is dependent on the presence of systemic metastasis. FNAB for prognostication has not been linked to multifocal uveal melanoma, nor was it implicated in our cases. Ocular melanocytosis is a risk factor for both unilateral multifocal and bilateral uveal melanoma. Although BAP1 mutation has been reported, its role in the development of multiple uveal melanoma requires further study. It is important to discuss the possibility of multiple uveal melanoma with patients as it may influence their treatment choice for globe-salvaging therapy. Examination of the treated as well as the contralateral eye at each follow-up visit is essential to identify new primary tumors as well as metastasis.

\section{Statement of Ethics}

This study was approved by the Duke University Health System Institutional Review Board with protocol ID: Pro00101974. It complies with the guidelines for human studies and was conducted ethically in accordance with the World Medical Association Declaration of Helsinki. Written consent was not required as the study consisted of a retrospective chart review that poses no more than minimal risk to participants. All cases have been de-identified in the text.

\section{Disclosure Statement}

The authors have no competing interests in this subject matter. Dr. Miguel A. Materin is a Consultant for Castle Biosciences and Idea Biosciences. Dr. Wajiha J. Kheir and Dr. Jane S. Kim have no financial interests to disclose.

\section{Funding Sources}

No funding was necessary for this project.

\section{Author Contributions}

J.S.K performed the chart review. W.J.K. interpreted the data. W.J.K. and M.A.M. were the major contributors in writing the manuscript.

\section{References}

1 Aronow ME, Topham AK, Singh AD. Uveal melanoma: 5-year update on incidence, treatment, and survival (SEER 1973-2013). Ocul Oncol Pathol. 2018 Apr;4(3):145-51.

2 Mahendraraj K, Lau CS, Lee I, Chamberlain RS. Trends in incidence, survival, and management of uveal melanoma: a populationbased study of 7,516 patients from the Surveillance, Epidemiology, and End Results database (1973-2012). Clin Ophthalmol. 2016 Oct;10:2113-9.

3 Singh AD, Turell ME, Topham AK. Uveal melanoma: trends in incidence, treatment, and survival. Ophthalmology. 2011 Sep; 118(9):1881-5.

4 Seregard S, Daunius C, Kock E, Popovic V. Two cases of primary bilateral malignant melanoma of the choroid. Br J Ophthalmol. 1988 Apr;72(4):244-5.
5 Shammas HF, Watzke RC. Bilateral choroidal melanomas. Case report and incidence. Arch Ophthalmol. 1977 Apr;95(4):617-23.

6 Singh AD, Shields CL, Shields JA, De Potter P. Bilateral primary uveal melanoma. Bad luck or bad genes? Ophthalmology. 1996 Feb; 103(2):256-62.

7 Hadden PW, Damato BE, McKay IC. Bilateral uveal melanoma: a series of four cases. Eye (Lond). 2003 Jul;17(5):613-6.

8 Lois N, Shields CL, Shields JA, De Potter P, Ramsey MS. Trifocal uveal melanom. Am J Ophthalmol. 1997 Dec;124(6):848-50.

9 Eide N, Garred Ø, Beiske K, Fodstad Ø. Bilateral uveal melanomas with different gene expression detected with 7 years interval. Acta Ophthalmol. 2016 Feb;94(1):99-102.

10 Kiratli H, Bilgiç S. Sequential development of bilateral primary choroidal melanoma. Acta Ophthalmol Scand. 2000 Aug;78(4):474-6.
11 Cordes FC, Cook RD. Simultaneous bilateral primary ocular malignant melanoma. Report of a case. Am J Ophthalmol. 1950 Dec;33(12): 1843-50.

12 Maheshwari A, Finger PT. Bilateral simultaneous primary choroidal melanomas: treated with palladium-103 plaque radiation. Eur J Ophthalmol. 2018 Sep;28(5):NP1-5.

13 Scott JF, Vyas R, Galvin J, Gotow E, Fiessinger L, Gerstenblith AT, et al. Primary bilateral uveal melanoma: a population-based study and systematic review. Clin Exp Ophthalmol. 2018 Jul;46(5):502-10.

14 Blumenthal EZ, Pe'er J. Multifocal choroidal malignant melanoma: at least 3 melanomas in one eye. Arch Ophthalmol. 1999 Feb;117(2): 255-8.

15 Hadden PW, Damato BE. Consecutive choroidal melanoma in the same eye of a patient. Am J Ophthalmol. 2003 May;135(5):728-9. 
16 Mustafi D, Damato B, Berry JL. Unilateral multifocal choroidal melanoma. Ocul Oncol Pathol. 2017 Dec;4(1):48-51.

17 Rao R, Pointdujour-Lim R, Ganguly A, Shields CL. Multifocal choroidal melanoma in a patient with germline BRCA-associated protein 1 mutation. Retin Cases Brief Rep. 2018;12(1):1-4.

18 Honavar SG, Shields CL, Singh AD, Demirci $\mathrm{H}$, Rutledge BK, Shields JA, et al. Two discrete choroidal melanomas in an eye with ocular melanocytosis. Surv Ophthalmol. 2002 JanFeb;47(1):36-41.

19 Pomeranz GA, Bunt AH, Kalina RE. Multifocal choroidal melanoma in ocular melanocytosis. Arch Ophthalmol. 1981 May;99(5): 857-63.

20 Sabates FN, Yamashita T. Congenital melanosis oculi complicated by two independent malignant melanomas of the choroid. Arch Ophthalmol. 1967 Jun;77(6):801-3.

21 Durante MA, Walter SD, Paez-Escamilla M, Tokarev J, Decatur CL, Dubovy SR, et al. Intraocular metastasis in unilateral multifocal uveal melanoma without melanocytosis or germline BAP1 mutations. JAMA Ophthalmol. 2019 Oct;137(12):1434-9.

22 Echegaray JJ, Medina CA, Biscotti CV, Plesec $\mathrm{T}$, Singh AD. Multifocal primary uveal melanoma: clinical and molecular characteristics. Ocul Oncol Pathol. 2019 Jan;5(1):8-12.

23 Morkos M, Jain P, Pavlick AC, Finger PT. Ipsilateral metastatic choroidal melanoma responds to systemic immunotherapy. Eur J Ophthalmol. 2019 Apr;1120672119839925.
24 Khetan V, Ambatipudi S, Gopal L. Presumed metastasis of choroidal melanoma to the contralateral choroid. Retin Cases Brief Rep. 2010;4(4):387-9.

25 Li J, Resnick K, Tso M. Metastasis of malignant melanoma of the choroid and ciliary body to the contralateral choroid. Graefes Arch Clin Exp Ophthalmol. 1993 Sep;231(9): 546-53.

26 Shields JA, Shields CL, Shakin EP, Kobetz LE. Metastasis of choroidal melanoma to the contralateral choroid, orbit, and eyelid. Br J Ophthalmol. 1988 Jun;72(6):456-60.

27 Singh AD, Shields JA, Shields CL, Sato T. Choroidal melanoma metastatic to the contralateral choroid. Am J Ophthalmol. 2001 Dec;132(6):941-3.

28 Torossian NM, Wallace RT, Hwu WJ, Bedikian AY. Metastasis of ciliary body melanoma to the contralateral eye: a case report and review of uveal melanoma literature. Case Rep Oncol Med. 2015;2015:427163.

29 Egan KM, Seddon JM, Glynn RJ, Gragoudas ES, Albert DM. Epidemiologic aspects of uveal melanoma. Surv Ophthalmol. 1988 JanFeb;32(4):239-51.

30 Scotto J, Fraumeni JF Jr, Lee JA. Melanomas of the eye and other noncutaneous sites: epidemiologic aspects. J Natl Cancer Inst. 1976 Mar;56(3):489-91.
31 Singh AD, De Potter P, Fijal BA, Shields CL, Shields JA, Elston RC. Lifetime prevalence of uveal melanoma in white patients with oculo(dermal) melanocytosis. Ophthalmology. 1998 Jan;105(1):195-8.

32 Finn AP, Materin MA, Mruthyunjaya P. Choroidal tumor biopsy. Retina. 2018 Sep;38:S7987.

33 Mashayekhi A, Lim RP, Shields CL, Eagle RC Jr, Shields JA. Extraocular extension of ciliochoroidal melanoma after transscleral fineneedle aspiration biopsy. Retin Cases Brief Rep. 2016;10(3):289-92.

34 Kim RS, Chevez-Barrios P, Bretana ME Wong TP, Teh BS, Schefler AC. Histopathologic analysis of transvitreal fine needle aspiration biopsy needle tracts for uveal melanoma. Am J Ophthalmol. 2017 Feb;174:9-16.

35 Turunen JA, Markkinen S, Wilska R, Saarinen S, Raivio V, Täll M, et al. BAP1 germline mutations in finnish patients with uveal melanoma. Ophthalmology. 2016 May;123(5):11127.

36 Gupta MP, Lane AM, DeAngelis MM, Mayne K, Crabtree M, Gragoudas ES, et al. Clinical characteristics of uveal melanoma in patients with germline BAP1 mutations. JAMA Ophthalmol. 2015 Aug;133(8):881-7.

37 Aoude LG, Vajdic CM, Kricker A, Armstrong $B$, Hayward NK. Prevalence of germline BAP1 mutation in a population-based sample of uveal melanoma cases. Pigment Cell Melanoma Res. 2013 Mar;26(2):278-9. 